\title{
Preoperative pulmonary function tests predict mortality after surgical or transcatheter aortic valve replacement
}

\author{
Matthew C. Henn, MD, ${ }^{a}$ Alan Zajarias, MD, ${ }^{\mathrm{b}}$ Brian R. Lindman, MD, ${ }^{\mathrm{b}}$ Jason W. Greenberg, BS, \\ Spencer J. Melby, MD, ${ }^{\mathrm{a}}$ Nishath Quader, MD, ${ }^{\mathrm{b}}$ Anna M. Vatterott, MPH, ${ }^{\mathrm{b}}$ Cassandra Lawler, MSN, \\ Marci S. Damiano, RN, MSN, ${ }^{\mathrm{b}}$ Eric Novak, MS, ${ }^{\mathrm{b}}$ John M. Lasala, MD, ${ }^{\mathrm{b}}$ Marc R. Moon, MD, \\ Jennifer S. Lawton, MD, ${ }^{\mathrm{a}}$ Ralph J. Damiano, Jr, MD, ${ }^{\mathrm{a}}$ and Hersh S. Maniar, MD
}

\begin{abstract}
Objectives: To determine the role of preoperative pulmonary function tests (PFTs) in patients with aortic stenosis (AS) evaluated for aortic valve replacement (AVR), and to evaluate the association between lung disease and mortality in specific subgroups.

Methods: Between 2008 and 2013, 535 patients with preoperative PFTs underwent AVR (transcatheter AVR [TAVR], $\mathrm{n}=246$; surgical AVR [SAVR], $\mathrm{n}=289$ ). The severity of lung disease determined by the Society of Thoracic Surgeons (STS) definition was evaluated in those with and without a clinical suspicion for lung disease (smoking, inhaled steroids/bronchodilators, or home oxygen). The association between lung disease and 1-year mortality was evaluated.
\end{abstract}

Results: Of the 186 patients (35\%) without suspected lung disease, 39 (21\%) had moderate/severe lung disease by PFT analysis. Among all patients, 1-year mortality was $12 \%$ in those with no lung disease, $17 \%$ in those with no mild lung disease, $22 \%$ in those with moderate lung disease, and $31 \%$ in those with severe lung disease $(P<.001, \log$-rank test). After adjustment, moderate/severe lung disease was associated with increased 1-year mortality (adjusted hazard ratio, 2.07; 95\% confidence interval, 1.30-3.29; $P=.002$ ); this association was not altered by smoking history, suspicion of lung disease, New York Heart Association class, or AVR type (interaction $P$ value nonsignificant for all).

Conclusions: In patients with AS evaluated for AVR, the STS risk score is significantly influenced by the severity of lung disease, which is determined predominantly by PFT results. Even when lung disease is not suspected, PFTs are abnormal in many patients undergoing AVR. Moderate/severe lung disease, diagnosed predominantly by PFTs, is an independent predictor of mortality after SAVR or TAVR. Collectively, these findings suggest that PFTs should be a routine part of the risk stratification of patients considered for AVR. (J Thorac Cardiovasc Surg 2016;151:578-86)
From the ${ }^{\mathrm{a} D i v i s i o n}$ of Cardiothoracic Surgery and ${ }^{\mathrm{b}}$ Cardiovascular Division, Washington University School of Medicine, Barnes-Jewish Hospital, St. Louis, Mo.

M.C.H. was supported by National Institutes of Health Grant T32 HL007776, and B.R.L. was supported by National Institutes of Health Grant K23 HL116660.

Read at the 95th Annual Meeting of The American Association for Thoracic Surgery, Seattle, Washington, April 25-29, 2015.

Received for publication May 4, 2015; revisions received Sept 1, 2015; accepted for publication Oct 6, 2015; available ahead of print Dec 11, 2015.

Address for reprints: Hersh S. Maniar, MD, Division of Cardiothoracic Surgery, Washington University School of Medicine, 660 S Euclid Ave, Campus Box 8234, St. Louis, MO 63110 (E-mail: maniarh@wudosis.wustl.edu).

$0022-5223 / \$ 36.00$

Copyright (c) 2016 by The American Association for Thoracic Surgery

http://dx.doi.org/10.1016/j.jtcvs.2015.10.067

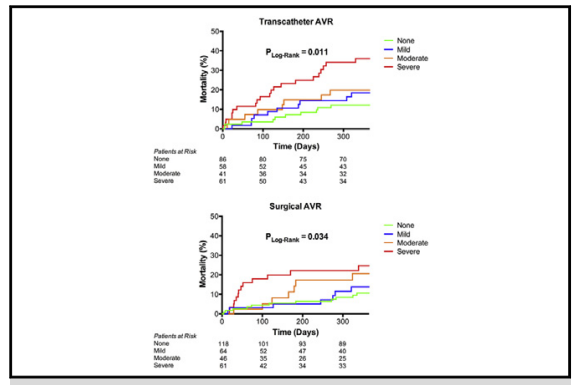

Chronic lung disease severity and all-cause mortality after aortic valve replacement.

\section{Central Message}

Even when unsuspected, lung disease is common in patients undergoing AVR and is associated with increased mortality.

\section{Perspective}

There is no consensus on who should undergo preoperative PFTs before AVR. Our results demonstrate that even when lung disease is not suspected, PFTs are abnormal in many patients. Further, moderate/severe lung disease is an independent predictor of mortality after SAVR or TAVR. These findings suggest that PFTs should be a routine part of the risk stratification of patients considered for AVR.

See Editorial Commentary page 587.

Scanning this QR code will take you to supplemental figure and tables for this article. To view the AATS 2015 Webcast, see the URL at the end of the article.

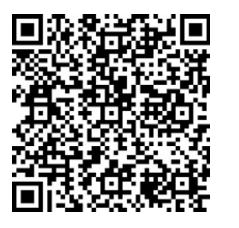

Chronic lung disease (CLD) is common in patients with aortic stenosis (AS) undergoing aortic valve replacement (AVR), and the presence and severity of CLD has been 


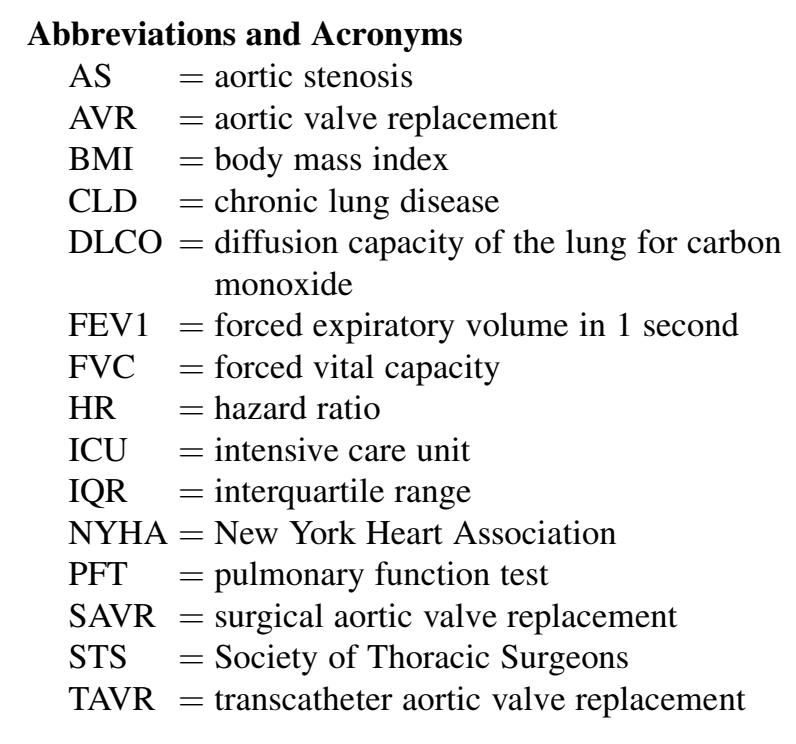

associated with increased mortality and morbidity after transcatheter aortic valve replacement (TAVR) and surgical aortic valve replacement (SAVR). ${ }^{1-4}$ Accordingly, CLD is an important component of several preoperative risk prediction scores, including the Society of Thoracic Surgeons (STS) risk score. ${ }^{1,5,6}$ In the STS database, CLD is determined largely based on results of pulmonary function tests (PFTs) ${ }^{6,7}$ There is no established consensus regarding which patients should undergo preoperative PFTs, however, and many centers perform this testing only in patients with suspected lung disease. Moreover, in patients with significant AS, whether abnormal PFTs are the result of intrinsic lung disease or of heart failure is a matter of debate. ${ }^{8}$ Given the evidence suggesting that PFTs improve after AVR, there is uncertainty regarding the underlying pathophysiology that abnormal preoperative PFTs reflect, and how these tests should be incorporated into an assessment of patient risk and treatment decisions. ${ }^{8}$

The purpose of the present study was to determine the utility of preoperative PFTs in patients with severe AS who were treated with AVR (TAVR or SAVR), and to assess the prevalence of CLD and its effect on mortality in this population. We hypothesized that moderate or severe CLD as determined by preoperative PFT results would be associated with increased mortality after AVR, and that this association would not be altered by smoking status, suspicion for lung disease, or severity of heart failure symptoms in patients with severe AS undergoing SAVR or TAVR.

\section{METHODS}

\section{Patient Population}

We retrospectively reviewed all patients age $>40$ years with severe AS (indexed valve area $\leq 0.6 \mathrm{~cm}^{2} / \mathrm{m}^{2}$, transvalvular mean gradient $>40 \mathrm{~mm}$
$\mathrm{Hg}$, or peak velocity $>4 \mathrm{~m} / \mathrm{s}$ ) who underwent preoperative PFTs before SAVR $(\mathrm{n}=289)$ or TAVR (transfemoral, $\mathrm{n}=102$; transapical, $\mathrm{n}=98$; transaortic, $n=46$ ) between 2008 and 2013 at our institution. In the SAVR group, patients who underwent concomitant coronary artery bypass graft surgery $(\mathrm{n}=82)$ were included, whereas patients undergoing any other valve procedures were excluded. Of the 1255 patients who underwent AVR at our institution during the study period, preoperative PFTs were performed in $91 \%$ (246 of 270) of those in the TAVR group and in $29 \%$ (289 of 985 ) of those in the SAVR group. PFTs were performed a median of 31 days before surgery. Outcomes were evaluated in the combined TAVR and SAVR groups and within each surgical approach. This study was conducted in accordance with the Declaration of Helsinki and was approved by Washington University School of Medicine's Institutional Review Board, from which a waiver of written informed consent was obtained, given the study's retrospective design.

\section{Clinical Data}

Baseline, perioperative, and postoperative clinical data were obtained from the STS database and from chart abstraction. The diagnosis of CLD was based on the STS definition, and the stratification of severity of lung disease was as follows ${ }^{7}$ : none; mild, forced expiratory volume in 1 second (FEV1) $60 \%$ to $75 \%$ of predicted, and/or on chronic inhaled or oral bronchodilator therapy; moderate, FEV1 $50 \%$ to $59 \%$ of predicted, and/or on chronic inhaled steroid therapy; severe, FEV1 $<50 \%$ of predicted and/or room air oxygen tension $<60 \mathrm{~mm} \mathrm{Hg}$ or room air carbon dioxide tension $>50 \mathrm{~mm} \mathrm{Hg}$.

All patients were also stratified by suspicion of lung disease regardless of their STS classification of CLD. For this study, suspected lung disease was defined as a history of smoking (current or past), bronchodilator or inhaled steroid use, or supplemental oxygen use. Based on these criteria, the patients were classified as with or without suspected lung disease, and the severity of CLD based on the STS definition was evaluated in each group.

\section{Statistical Analysis}

Patients with no lung disease or mild lung disease were combined into a single group and compared with those with moderate or severe lung disease. Comparisons of baseline clinical, procedural, and postprocedural characteristics between groups were performed using the Student 2-sample $t$ test or Fisher's exact test for continuous and categorical data, respectively. For nonnormal and ordinal data, summary statistics are provided as median and interquartile range, and between-group comparisons were performed using the Kruskal-Wallis test.

Surgery date served as the start time, and follow-up was completed through October 2014. Kaplan-Meier estimates were stratified by lung disease severity, and the log-rank test was used to compare survival distributions. A multivariable Cox proportional hazards model was constructed to evaluate the association between lung disease severity and 1-year all-cause mortality in the combined SAVR and TAVR population while adjusting for covariates including age, sex, body mass index (BMI), diabetes, previous infarct, New York Heart Association (NYHA) class, atrial fibrillation, smoking, glomerular filtration rate, left ventricular ejection fraction, and AVR type, all of which have been associated with mortality in this population.

In addition, a multivariable Cox proportional hazards model was built with the aforementioned covariates along with the appropriate corresponding interaction, to determine whether the association between moderate/severe CLD and mortality differed with respect to subgroups defined by the following variables: smoking status, AVR type (TAVR vs 
TABLE 1. Suspected versus actual lung disease based on PFT results

\begin{tabular}{|c|c|c|c|}
\hline Variable & $\begin{array}{l}\text { No suspected } \\
\text { lung disease }\end{array}$ & $\begin{array}{c}\text { Suspected } \\
\text { lung disease* }\end{array}$ & $\begin{array}{c}P \\
\text { value }\end{array}$ \\
\hline TAVR-treated, $\mathrm{n}$ & 91 & 155 & \\
\hline Lung disease severity, n (\%) $\dagger$ & & & $<.001$ \\
\hline None & $49(54)$ & $37(24)$ & \\
\hline Mild & $19(21)$ & $39(25)$ & \\
\hline Moderate & $14(15)$ & $27(17)$ & \\
\hline Severe & $9(10)$ & $52(34)$ & \\
\hline $\begin{array}{l}\text { Moderate/severe lung disease, } \\
\mathrm{n}(\%) \dagger\end{array}$ & $23(25)$ & $79(51)$ & $<.001$ \\
\hline SAVR-treated, $\mathrm{n}$ & 95 & 194 & \\
\hline Lung disease severity, n $(\%) \dagger$ & & & $<.001$ \\
\hline None & $61(64)$ & $57(29)$ & \\
\hline Mild & $18(19)$ & $46(24)$ & \\
\hline Moderate & $10(11)$ & $36(19)$ & \\
\hline Severe & $6(6)$ & $55(28)$ & \\
\hline $\begin{array}{l}\text { Moderate/severe lung disease, } \\
\mathrm{n}(\%) \dagger\end{array}$ & $16(17)$ & $91(47)$ & $<.001$ \\
\hline
\end{tabular}

SAVR), suspicion of lung disease, and NYHA class III or IV heart failure. A separate multivariable model was built for each interaction comparing subgroups. A 2 -sided $P$ value $<.05$ was considered significant. All statistical analyses were conducted using SAS 9.4 (SAS Institute, Cary, NC).

\section{RESULTS}

In the entire cohort $(n=535)$, the prevalence of lung disease determined by STS definition was as follows: none, $38 \%(\mathrm{n}=204)$; mild, $23 \%(\mathrm{n}=122)$; moderate, $16 \%(\mathrm{n}=87)$; severe, $23 \%(\mathrm{n}=122)$. Of the 186 patients $(35 \%)$ without suspicion for lung disease, $39(21 \%)$ had moderate or severe CLD according to the STS definition. Among the 349 patients with some suspicion for lung disease, $255(73 \%)$ had some degree of CLD based on STS criteria, including 63 with moderate CLD (18\%) and 107 with severe CLD (31\%). Regardless of any suspicion for lung disease, $39 \%$ of the entire cohort (209 of 535) had moderate/severe CLD based on preoperative PFTs and the STS criteria for CLD. The presence and severity of lung disease in the TAVR and SAVR groups according to whether or not lung disease was suspected are reported in Table 1.

\section{Patient Demographics for TAVR and SAVR}

Overall, patients with moderate/severe CLD were sicker in both the TAVR and SAVR groups. In the overall AVR cohort, compared with patients with no/mild CLD, those with moderate/severe CLD were younger (mean age, 76.2 years vs 78.9 years; $P=.003$ ) and had more NYHA class III/IV heart failure ( $90 \%$ [ 189 of 209] vs $78 \%$ [254 of 326]; $P<.001)$, more atrial arrhythmias $(42 \%$ [88 of 209] vs $31 \%$ [100 of 326]; $P=.007$ ), and higher STS risk scores $(10.2$ vs $7.4 ; P<.001)$. In the TAVR group, compared with patients with no/mild CLD, those with moderate/severe CLD were younger, had higher STS risk scores, and more NYHA class III/IV heart failure (Table 2). These results were consistent with those in the SAVR group; however, in that group, patients with moderate/severe CLD also had more peripheral artery disease and atrial arrhythmias compared with those with no/mild CLD (Table 2).

Interestingly, there was no difference in the prevalence of smoking between patients with no/mild CLD and those with moderate/severe CLD in either the TAVR or SAVR group (Table 2). There were also no differences in BMI, ejection fraction, glomerular filtration rate, or in the prevalence of cerebrovascular disease, coronary disease, or diabetes (Table 2).

\section{Perioperative Morbidity and Mortality}

In the overall AVR cohort, compared with patients with no/mild CLD, those with moderate/severe CLD had higher 30 -day mortality ( $7 \%$ vs $3 \% ; P=.035$ ), a longer median intensive care unit (ICU) stay (48 hours [interquartile range (IQR), 26-116 hours] vs 30 hours [IQR, 24-68 hours]; $P<.001)$, more ICU readmissions $(11 \%$ vs $5 \%$; $P=.009)$, and more ICU readmissions secondary to respiratory failure (56\% [12 of 22] vs $20 \%$ [ 3 of 15 ]; $P=.036$ ).

In the SAVR group, patients with moderate/severe CLD had significantly longer ICU stays compared with those with no/mild CLD (median, 76 hours [IQR, 44-142 hours] vs 47 hours [IQR, 25-78 hours]; $P<.001$ ) and longer hospital stays (median, 8 days [IQR, 6-12 days] vs 11 days [IQR, $7-17$ days]; $P<.001$ ). In the TAVR group, compared with patients with no/mild CLD, those with moderate/severe CLD had a longer ICU stay (median 28 hours [IQR, 24-52 hours] vs 25 hours [IQR, 2344 hours]; $P=.024$ ), more ICU readmissions ( $9 \%$ vs $2 \% ; P=.017)$, and a trend toward a longer hospital stay (Table 3 ). In both populations, there were no differences in intraoperative blood product administration, intra-aortic balloon pump insertion, acute kidney injury, perioperative stroke, intubation for $>24$ hours, or 30-day mortality (Table 3).

\section{One-Year Mortality}

Based on a Kaplan-Meier estimates, 1-year mortality was $12 \%$ in patients with no lung disease, $17 \%$ in those with mild lung disease, $22 \%$ in those with moderate lung disease, and $31 \%$ in those with severe lung disease 
TABLE 2. Baseline clinical characteristics

\begin{tabular}{|c|c|c|c|c|c|c|c|c|}
\hline \multirow[b]{2}{*}{ Characteristic } & \multicolumn{4}{|c|}{ TAVR } & \multicolumn{4}{|c|}{ SAVR } \\
\hline & $\begin{array}{c}\text { Overall } \\
(n=246)\end{array}$ & $\begin{array}{c}\text { No/mild CLD } \\
(n=144)\end{array}$ & $\begin{array}{c}\text { Moderate/ } \\
\text { severe CLD* } \\
(\mathbf{n}=\mathbf{1 0 2})\end{array}$ & $P$ value & $\begin{array}{c}\text { Overall } \\
(\mathbf{n}=\mathbf{2 8 9})\end{array}$ & $\begin{array}{l}\text { No/mild CLD } \\
\quad(\mathbf{n}=182)\end{array}$ & $\begin{array}{c}\text { Moderate/ } \\
\text { severe CLD* } \\
(\mathbf{n}=\mathbf{1 0 7})\end{array}$ & $\begin{array}{c}P \\
\text { value } \\
\end{array}$ \\
\hline Age, yr, mean \pm SD & $81 \pm 9$ & $83 \pm 8$ & $80 \pm 9$ & .005 & $75 \pm 11$ & $76 \pm 11$ & $73 \pm 10$ & .023 \\
\hline Female sex, $\mathrm{n}$ & 49 & 45 & 54 & .20 & 43 & 38 & 50 & .08 \\
\hline Body mass index, mean $\pm \mathrm{SD}$ & $27.6 \pm 6.1$ & $27.0 \pm 5.0$ & $28.5 \pm 7.3$ & .07 & $30.6 \pm 8.2$ & $30.7 \pm 8.0$ & $30.2 \pm 8.4$ & .62 \\
\hline STS score, mean \pm SD & $10.4 \pm 5.6$ & $9.0 \pm 4.6$ & $12.5 \pm 6.2$ & $<.001$ & $6.9 \pm 5.5$ & $6.2 \pm 4.8$ & $8.0 \pm 6.3$ & .010 \\
\hline Diabetes, $\mathrm{n}$ & 41 & 39 & 45 & .36 & 43 & 42 & 44 & .81 \\
\hline Insulin treated, $\mathrm{n}$ & 20 & 17 & 23 & .33 & 16 & 15 & 18 & .62 \\
\hline Hypertension, $\mathrm{n}$ & 93 & 95 & 91 & .29 & 84 & 87 & 79 & .13 \\
\hline Coronary disease, $\mathrm{n}$ & 85 & 86 & 82 & .48 & 67 & 67 & 66 & 1.00 \\
\hline Previous cardiovascular surgery, $\mathrm{n}$ & 54 & 56 & 51 & .52 & 26 & 29 & 21 & .13 \\
\hline NYHA class III/IV, n & 88 & 84 & 93 & .047 & 79 & 73 & 88 & .003 \\
\hline Atrial arrhythmia, n & 38 & 35 & 41 & .42 & 33 & 27 & 43 & .006 \\
\hline Smoker, $\mathrm{n}$ & 49 & 44 & 55 & .12 & 56 & 52 & 62 & .14 \\
\hline Immunocompromised state, $\mathrm{n} \dagger$ & 12 & 11 & 14 & .56 & 8 & 6 & 10 & .25 \\
\hline Peripheral arterial disease, $\mathrm{n}$ & 61 & 63 & 57 & .35 & 37 & 32 & 46 & .023 \\
\hline Cerebrovascular disease, $\mathrm{n}$ & 34 & 33 & 35 & .79 & 26 & 27 & 25 & .78 \\
\hline \multicolumn{9}{|l|}{ Laboratory values, mean $\pm \mathrm{SD}$} \\
\hline Hemoglobin, g/dL & $11.4 \pm 1.5$ & $11.5 \pm 1.5$ & $11.3 \pm 1.6$ & .44 & $12.0 \pm 1.7$ & $12.2 \pm 1.7$ & $11.6 \pm 1.7$ & .004 \\
\hline $\begin{array}{l}\text { Glomerular filtration rate, } \\
\mathrm{mL} / \mathrm{min} / 1.73 \mathrm{~m}^{2}\end{array}$ & $64 \pm 27$ & $62 \pm 20$ & $67 \pm 34$ & .18 & $68 \pm 27$ & $65 \pm 23$ & $71 \pm 32$ & .09 \\
\hline Albumin, g/dL & $4.1 \pm 0.4$ & $4.0 \pm 0.4$ & $4.1 \pm 0.4$ & .042 & $4.0 \pm 0.4$ & $4.1 \pm 0.4$ & $3.9 \pm 0.5$ & .009 \\
\hline \multicolumn{9}{|l|}{ Pulmonary function tests, mean \pm SD } \\
\hline Forced expiratory volume in $1 \mathrm{~s}, \mathrm{~L}$ & $1.6 \pm 0.6$ & $1.9 \pm 0.5$ & $1.3 \pm 0.6$ & $<.001$ & $2.0 \pm 0.8$ & $2.2 \pm 0.7$ & $1.6 \pm 0.8$ & $<.001$ \\
\hline Percent predicted, $\%$ & $72 \pm 25$ & $86 \pm 20$ & $52 \pm 18$ & $<.001$ & $74 \pm 24$ & $87 \pm 17$ & $53 \pm 18$ & $<.001$ \\
\hline Forced vital capacity, L & $2.3 \pm 0.8$ & $2.6 \pm 0.8$ & $2.0 \pm 0.8$ & $<.001$ & $2.8 \pm 0.9$ & $3.0 \pm 0.8$ & $2.4 \pm 1.0$ & $<.001$ \\
\hline Percent predicted, $\%$ & $77.1 \pm 23.4$ & $87.2 \pm 18.9$ & $62.6 \pm 21.5$ & $<.001$ & $82.2 \pm 22.0$ & $90.9 \pm 18.5$ & $67.4 \pm 19.4$ & $<.001$ \\
\hline DLCO percent predicted, $\%$ & $103.8 \pm 36.9$ & $105.3 \pm 33.4$ & $101.5 \pm 41.7$ & .48 & $98.8 \pm 30.5$ & $104.7 \pm 27.6$ & $87.5 \pm 32.7$ & $<.001$ \\
\hline $\mathrm{PaO}_{2}, \mathrm{mmHg}$, on room air & $76.4 \pm 13.2$ & $80.6 \pm 8.9$ & $71.0 \pm 15.8$ & $<.001$ & $73.6 \pm 12.5$ & $78.7 \pm 9.1$ & $66.2 \pm 13.1$ & $<.001$ \\
\hline $\mathrm{PaCO}_{2}, \mathrm{mmHg}$, on room air & $41 \pm 7$ & $39 \pm 5$ & $43 \pm 9$ & .006 & $40 \pm 6$ & $39 \pm 4$ & $42 \pm 7$ & $<.001$ \\
\hline \multicolumn{9}{|l|}{ Echocardiography } \\
\hline Ejection fraction, $\%$, mean $\pm \mathrm{SD}$ & $53 \pm 15$ & $53 \pm 15$ & $54 \pm 15$ & 0.84 & $54 \pm 15$ & $54 \pm 14$ & $53 \pm 16$ & .45 \\
\hline Mean gradient, $\mathrm{mmHg}$, mean $\pm \mathrm{SD}$ & $42 \pm 13$ & $43 \pm 13$ & $41 \pm 13$ & .32 & $42 \pm 14$ & $42 \pm 13$ & $42 \pm 16$ & .76 \\
\hline Moderate or severe AR, $\%$ & 13 & 12 & 14 & .70 & 16 & 13 & 21 & .13 \\
\hline Moderate or severe MR, \% & 20 & 21 & 19 & .74 & 14 & 12 & 17 & .21 \\
\hline Moderate or severe TR, $\%$ & 11 & 6 & 19 & .004 & 7 & 8 & 4 & .22 \\
\hline $\begin{array}{l}\text { Pulmonary artery systolic pressure, } \\
\mathrm{mm} \mathrm{Hg}, \text { mean } \pm \mathrm{SD}\end{array}$ & $48 \pm 16$ & $46 \pm 15$ & $51 \pm 17$ & 0.05 & $46 \pm 15$ & $43 \pm 14$ & $50 \pm 15$ & .003 \\
\hline
\end{tabular}

Groups were compared using the Student 2-sample $t$ test or Fisher's exact test for continuous and categorical variables, respectively. Nonnormal and ordinal variables were compared using the Kruskal-Wallis test. TAVR, Transcatheter aortic valve replacement; $S A V R$, surgical aortic valve replacement; $C L D$, chronic lung disease; $S D$, standard deviation; STS, Society of Thoracic Surgeons; NYHA, New York Heart Association; DLCO, diffusion capacity of the lung for carbon monoxide; Pao ${ }_{2}$, arterial oxygen tension; $\mathrm{PaCO}_{2}$, arterial carbon dioxide tension; $A R$, aortic regurgitation; $M R$, mitral regurgitation; $T R$, tricuspid regurgitation. ${ }^{*}$ Moderate/severe $\mathrm{CLD}$ includes moderate or severe chronic lung disease based on STS criteria. †Excludes any one-time administration of corticosteroids perioperatively.

$(P<.001$, log-rank) (Figure 1 and Table E1). In subgroup analysis, no, mild, moderate, and severe lung disease were associated with a 1 -year mortality of $12 \%, 18 \%, 20 \%$, and $36 \%$, respectively, in the TAVR group $(P=.011$, log-rank test) and $11 \%, 14 \%, 21 \%$, and $25 \%$, respectively, in the SAVR group $(P=.034, \log$-rank test) (Figure 1 and Table E1). Also based on Kaplan-Meier estimates, the survival of patients with no/mild CLD and those with moderate/severe CLD remained significantly different in the overall cohort $(P<.001, \log$-rank test $)$, the SAVR group $(P=.011, \log$-rank test $)$, and the TAVR group $(P=.005$, log-rank test).

When all patients were stratified into quartiles based on raw PFT data, 1-year mortality was significantly different in the 4 quartiles of FEV1 percent predicted $(P=.006$, log-rank test) and in the 4 quartiles of diffusion capacity of the lung for carbon monoxide (DLCO) percent predicted $(P=.005$, log-rank test) (Figure E1 and Table E2); 
TABLE 3. Procedural and postprocedural characteristics

\begin{tabular}{|c|c|c|c|c|c|c|c|c|}
\hline \multirow[b]{2}{*}{ Characteristic } & \multicolumn{4}{|c|}{ TAVR } & \multicolumn{4}{|c|}{ SAVR } \\
\hline & $\begin{array}{c}\text { Overall } \\
(n=246)\end{array}$ & $\begin{array}{c}\text { No/mild } \\
\text { CLD } \\
(n=144)\end{array}$ & $\begin{array}{c}\text { Moderate/ } \\
\text { severe CLD* } \\
(\mathbf{n}=\mathbf{1 0 2})\end{array}$ & $\begin{array}{c}P \\
\text { value }\end{array}$ & $\begin{array}{c}\text { Overall } \\
(\mathbf{n}=\mathbf{2 8 9})\end{array}$ & $\begin{array}{c}\text { No/mild } \\
\text { CLD } \\
(n=182)\end{array}$ & $\begin{array}{c}\text { Moderate/ } \\
\text { severe CLD* } \\
(\mathbf{n}=\mathbf{1 0 7})\end{array}$ & $\begin{array}{c}P \\
\text { value }\end{array}$ \\
\hline $\mathrm{CABG}, \mathrm{n}$ & & & & & 28 & 29 & 28 & 1.00 \\
\hline Cardiopulmonary bypass, $\mathrm{n}$ & 4 & 6 & 2 & .20 & 99 & 99 & 99 & 1.00 \\
\hline $\begin{array}{l}\text { Bypass time min, } \\
\text { mean } \pm \mathrm{SD}\end{array}$ & N/A & N/A & N/A & & $123 \pm 39$ & $124 \pm 40$ & $121 \pm 37$ & .53 \\
\hline $\begin{array}{l}\text { Crossclamp time, min, } \\
\text { mean } \pm \text { SD }\end{array}$ & N/A & N/A & N/A & & $85 \pm 30$ & $86 \pm 31$ & $83 \pm 29$ & .33 \\
\hline $\begin{array}{l}\text { Intraoperative blood products } \\
\text { used, } n\end{array}$ & 41 & 43 & 39 & .51 & 88 & 87 & 89 & .71 \\
\hline Red blood cells & 37 & 40 & 34 & .42 & 80 & 80 & 79 & 1.00 \\
\hline Fresh frozen plasma & 3 & 3 & 3 & 1.00 & 40 & 41 & 39 & .90 \\
\hline Cryoprecipitate & 1 & 1 & 1 & 1.00 & 26 & 26 & 26 & 1.00 \\
\hline Platelets & 11 & 13 & 8 & .22 & 60 & 62 & 57 & .46 \\
\hline Fibrinolytics (intraoperative), $\mathrm{n}$ & 2 & 2 & 3 & .69 & 90 & 89 & 92 & .68 \\
\hline $\begin{array}{l}\text { IABP (preoperative or } \\
\text { intraoperative), } \mathrm{n}\end{array}$ & 2 & 1 & 3 & .31 & 6 & 5 & 8 & .31 \\
\hline Vascular complications, $\mathrm{n}$ & 21 & 20 & 22 & 1.00 & 0 & 0 & 0 & 1.00 \\
\hline Intubation $>24 \mathrm{~h}, \mathrm{n}$ & 1 & 1 & 1 & 1.00 & 11 & 10 & 13 & .33 \\
\hline \multicolumn{9}{|l|}{ Postprocedural } \\
\hline Stroke within $24 \mathrm{~h}$ of AVR, $\mathrm{n}$ & 1 & 1 & 1 & 1.00 & 1 & 1 & 1 & 1.00 \\
\hline Acute kidney injury, $\mathrm{n}$ & 12 & 9 & 17 & .08 & 20 & 20 & 21 & .88 \\
\hline $\begin{array}{l}\text { Hospital LOS, d, } \\
\text { median (IQR) }\end{array}$ & $5(4,8)$ & $5(4,7)$ & $6(5,9)$ & .12 & $9(7,14)$ & $8(6,12)$ & $11(7-17)$ & $<.001$ \\
\hline ICU hours, mean $\pm \mathrm{SD}$ & $26.3(23.2-47.3)$ & $25.3(23.0-43.9)$ & $28.0(23.8-51.8)$ & .024 & $52.4(27.0-109.3)$ & $47.2(25.2-78.0)$ & $76.3(43.8-142.0)$ & $<.001$ \\
\hline ICU readmission, $\mathrm{n}(\%)$ & $12(5)$ & $3(2)$ & $9(9)$ & .017 & $25(9)$ & $12(7)$ & $13(12)$ & .13 \\
\hline $\begin{array}{l}\text { Respiratory readmission, } \dagger \\
\text { n (\%) }\end{array}$ & $7(58)$ & $1(33)$ & $6(67)$ & .52 & $8(32)$ & $2(17)$ & $6(46)$ & .20 \\
\hline $\begin{array}{l}\text { Perioperative mortality, } \\
\mathrm{n}(\%)\end{array}$ & $13(5)$ & $5(3)$ & $8(8)$ & .15 & $12(4)$ & $5(3)$ & $7(7)$ & .13 \\
\hline
\end{tabular}

$\overline{T A V R}$, Transcatheter aortic valve replacement; $S A V R$, surgical aortic valve replacement; $C L D$, chronic lung disease; $C A B G$, coronary artery bypass graft; $S D$, standard deviation; $N / A$, not applicable; $I A B P$, intra-aortic balloon pump; $A V R$, aortic valve replacement; $L O S$, length of stay; $I Q R$, interquartile range; $I C U$, intensive care unit. *Moderate/severe CLD includes moderate or severe CLD based on Society of Thoracic Surgeons criteria. $†$ Number and percent of ICU readmissions secondary to respiratory distress. Groups were compared using the Student 2-sample $t$ test or Fisher's exact test, for continuous and categorical variables, respectively. Nonnormal and ordinal variables were compared using the Kruskal-Wallis test.

however, 1-year mortality was not significantly different among the 4 quartiles of forced vital capacity (FVC) percent predicted $(P=.06$, log-rank test). When evaluated as continuous variables, all 3 PFT metrics (FEV1, FVC, and DLCO) were associated with increased 1-year mortality per $10 \%$ decrease (Table E3).

After adjustment for age, sex, BMI, diabetes, previous infarct, NYHA class, atrial fibrillation, smoking, glomerular filtration rate, left ventricular ejection fraction, and AVR type, moderate/severe CLD was associated with increased risk for 1-year mortality (adjusted hazard ratio $[\mathrm{HR}], \quad 2.07 ; 95 \% \quad \mathrm{CI}, \quad 1.30-3.29$; $P=.002$ ) (Table 4). Of note, there was no interaction between CLD severity and smoking history, AVR type, NYHA class, or suspicion of lung disease with respect to 1-year mortality (interaction $P$ value nonsignificant for all) (Table 4). Finally, among patients with moderate/severe CLD, there was no difference in risk for mortality at 1 year between patients who underwent nontransfemoral TAVR and those who underwent transfemoral TAVR (adjusted HR, 2.42; 95\% CI, 1.14-5.12 vs adjusted HR, 1.57; 95\% CI, 0.69-3.58; $P=.45$ ); however, the present study was underpowered to fully evaluate this interaction.

\section{DISCUSSION}

In our study population, the majority of patients treated with TAVR or SAVR had lung disease according to a PFT-based definition. Even when lung disease was not suspected, PFTs are abnormal in many of these patients, including approximately $20 \%$ with moderate/severe lung disease. Moderate/severe lung disease is an independent predictor of mortality after SAVR or TAVR regardless of smoking history, suspicion for lung disease, or severity of heart failure symptoms. In 


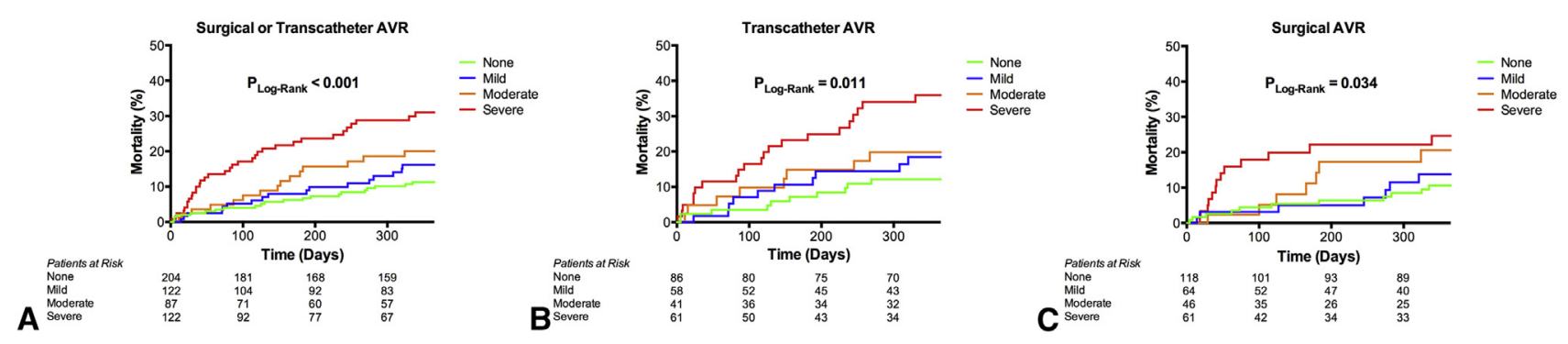

FIGURE 1. CLD and mortality after AVR. Time-to-event curves are shown based on Kaplan-Meier estimates with patients stratified by STS lung disease severity for (A) TAVR and SAVR combined, (B) TAVR alone, and (C) SAVR alone. AVR, Aortic valve replacement.

additiony, moderate/severe lung disease is associated with increased ICU utilization. Collectively, these findings demonstrate that a PFT-based diagnosis of lung disease has consistent prognostic significance and suggest that PFTs should be a routine part of the risk stratification of patients considered for AVR.

Previously reported estimates of the prevalence of CLD in patients undergoing aortic valve intervention for severe AS have ranged from $16 \%$ to $30 \%{ }^{3,9,10}$ In the present study, we found a higher percentage of patients with CLD than was previously reported, likely owing to a sicker cohort of patients. With the introduction of TAVR, more high-risk patients are being offered intervention, which is likely increasing the number of patients with CLD receiving intervention. ${ }^{11,12}$ Our numbers are more consistent with recent studies from the PARTNER trial, which report CLD in nearly $45 \%$ of patients who underwent TAVR. ${ }^{2,13,14}$

In the present study, moderate/severe CLD is associated with increased mortality, which is consistent with literature reports in patients undergoing $\mathrm{TAVR}^{2,3,15,16}$ and

TABLE 4. Impact of lung disease on 1-year mortality in adjusted analyses for SAVR and TAVR combined

\begin{tabular}{lcc}
\hline \multicolumn{1}{c}{ Variable } & HR $(\mathbf{9 5} \%$ CI $)$ & $P$ value \\
\hline Overall adjusted moderate/severe & $2.069(1.302-3.285)$ & .002 \\
$\quad$ & & \\
lung disease* & & \\
Interactions with lung disease severity & on 1-y mortality & \\
$\quad$ Smoker & $2.288(1.288-4.064)$ & .56 \\
Nonsmoker & $1.729(0.812-3.683)$ & \\
TAVR & $2.033(1.120-3.692)$ & .93 \\
SAVR & $2.116(1.074-4.168)$ & \\
NYHA class I/II & $1.058(0.109-10.278)$ & .55 \\
NYHA class III/IV & $2.138(1.329-3.439)$ & \\
Suspected lung disease & $2.001(1.176-3.405)$ & .76 \\
Not suspected lung disease & $1.687(0.622-4.576)$ & \\
\hline
\end{tabular}

HR, Hazard ratio; $C I$, confidence interval; TAVR, transcatheter aortic valve replacement; SAVR, surgical aortic valve replacement; NYHA, New York Heart Association. *After adjustment for age, sex, body mass index, diabetes, previous infarct, NYHA class, atrial fibrillation, smoking, glomerular filtration rate, left ventricular ejection fraction, and type of aortic valve replacement.
SAVR. ${ }^{1,4,17}$ A study from the STS database that included 9177 patients with preoperative PFTs who underwent SAVR for AS demonstrated independent associations between moderate/severe CLD and operative mortality (OR, 2.88; 95\% CI, 2.0-4.5), pulmonary morbidity (OR, 2.33; 95\% CI, 1.93-2.8), and prolonged hospital stay (OR, 7.73; 95\% CI, 2.17-3.45). ${ }^{1}$ Dvir and colleagues ${ }^{2}$ reported data from the PARTNER trial, which included 2553 patients who underwent TAVR, and found a higher mortality rate at 1 -year follow-up for patients with CLD compared with those without CLD (23.4\% vs $19.6 \%$; $P=.02$ ). In contrast to those reports, however, several other trials did not identify CLD as an independent predictor for mortality. 8,18

The diagnosis of CLD according to the STS definition ${ }^{7}$ is based primarily on PFT results, particularly FEV1; howev$\mathrm{er}$, there is some evidence that airway edema from congestive heart failure in patients with AS may cause elevated FEV1 and lead to overestimation of the prevalence of CLD in this population. ${ }^{1,8}$ Magee and colleagues ${ }^{8}$ reported that $42 \%$ to $50 \%$ of patients enrolled in the PARTNER trial at their institution demonstrated at least a $10 \%$ improvement in FEV1 values after intervention. This finding has raised concerns about the prognostic significance of a PFT-based diagnosis of lung disease in patients with severe AS; however, our data suggest that regardless of the reason for the abnormal PFT results, and despite the fact that they may improve after AVR in some patients, the prognostic significance of moderate/severe CLD (based largely on PFTs) is consistent regardless of smoking history, suspicion of lung disease, NYHA class, or AVR type.

Despite the association of CLD with mortality and other clinical outcomes after AVR, there is no current consensus on which patients being evaluated for SAVR or TAVR should undergo preoperative PFTs. Although we acknowledge the importance of a cost-effective preoperative evaluation, in an era when TAVR is a viable alternative to SAVR for higher-risk patients, it is important to accurately assess each patient's preoperative risk to clarify his or her treatment options. ${ }^{19}$ Clinical history alone has 
proven inadequate for accurately identifying risk secondary to CLD in patients undergoing cardiac surgery. Adabag and colleagues $^{20}$ reviewed 1169 patients undergoing cardiac surgery and demonstrated that PFTs reclassified the COPD status in $31 \%$ of patients, including identifying new CLD in $16 \%$ of the cohort. Ad and colleagues ${ }^{21}$ reported similar results in a prospective cohort of 220 patients undergoing cardiac surgery who were at high risk for CLD based on smoking status, history of asthma, home oxygen use, or persistent cough. They found a significant underestimation of the prevalence and severity of CLD when using the STS definitions without spirometry, including detecting severe CLD in $12 \%$ of patients previously classified as having no CLD or mild CLD. These results are consistent with the present study, which is the first to report that in patients with severe AS undergoing either TAVR or SAVR, $21 \%$ of those without suspected lung disease had moderate/severe CLD based on PFT results.

Other PFT indices besides FEV1 have been explored as predictors of outcomes in the severe AS population. In the SAVR-treated population, low predicted DLCO and low arterial oxygen tension have been associated with increased mortality and pulmonary complications, ${ }^{1,20}$ whereas low predicted FVC also has been loosely associated with in-hospital mortality. ${ }^{22}$ Other PFT indices besides FEV1 have not been closely evaluated in the TAVR population, however. In the present study, we were able to demonstrate significant differences in 1-year mortality in patients stratified into quartiles based on preoperative DLCO and FEV1 values, but the quartiles of FVC did not reach statistical significance. Further studies are needed to determine whether there are better ways to refine risk stratification related to CLD for patients evaluated for AVR.

The present study has some limitations. It is based on preoperative PFTs, which are not obtained routinely in every patient undergoing either TAVR or SAVR. This introduces a selection bias that may select for patients with some clinical suspicion of lung disease other than the criteria that we used, particularly in the SAVR population. However, with the widespread application of TAVR, every patient referred to our institution for TAVR undergoes preoperative PFTs, which reduces this selection bias. Another limitation is the possibility of potential unidentified confounding variables despite multivariate adjustments. Still another is the lack of standardization of the interval between PFTs and surgery, which potentially could confound our results. Finally, this was a single-center, retrospective study from a high-volume TAVR and SAVR institution, and so the results might not be generalizable.

\section{CONCLUSIONS}

This study demonstrates that a majority of patients who undergo TAVR or SAVR for severe AS have abnormal PFT results, and that $21 \%$ of patients without any suspicion for lung disease had moderate or severe lung disease on evaluation. The consistency of the adverse association between moderate/severe lung disease and mortality after AVR suggests that PFTs should be a routine part of the preoperative workup for patients with severe AS undergoing AVR.

\section{Conflict of Interest Statement}

R.J.D. has received educational funding from Edwards Lifesciences. A.Z. is a consultant for Edwards Lifesciences. B.R.L. receives grants and personal fees from Roche Diagnostics. All other authors have nothing to disclose with regard to commercial support.

You can watch a Webcast of this AATS meeting presentation by going to: http://webcast.aats.org/2015/Video/ Monday/04-27-15_608_1630_Henn.mp4.

\section{References}

1. Crestanello JA, Higgins RS, He X, Saha-Chaudhuri P, Englum BR, Brennan JM, et al. The association of chronic lung disease with early mortality and respiratory adverse events after aortic valve replacement. Ann Thorac Surg. 2014;98: 2068-77.

2. Dvir D, Waksman R, Barbash IM, Kodali SK, Svensson LG, Tuzcu EM, et al. Outcomes of patients with chronic lung disease and severe aortic stenosis treated with transcatheter versus surgical aortic valve replacement or standard therapy: insights from the PARTNER trial (placement of AoRTic TraNscathetER Valve). $J$ Am Coll Cardiol. 2014;63:269-79.

3. Mok M, Nombela-Franco L, Dumont E, Urena M, DeLarochellière R, Doyle D, et al. Chronic obstructive pulmonary disease in patients undergoing transcatheter aortic valve implantation: insights on clinical outcomes, prognostic markers, and functional status changes. JACC Cardiovasc Interv. 2013;6:1072-84.

4. Gunter RL, Kilgo P, Guyton RA, Chen EP, Puskas JD, Cooper WA, et al. Impact of preoperative chronic lung disease on survival after surgical aortic valve replacement. Ann Thorac Surg. 2013;96:1322-8.

5. Brown JM, O'Brien SM, Wu C, Sikora JA, Griffith BP, Gammie JS. Isolated aortic valve replacement in North America comprising 108,687 patients in 10 years: changes in risks, valve types, and outcomes in the Society of Thoracic Surgeons National Database. J Thorac Cardiovasc Surg. 2009;137: 82-90.

6. Society of Thoracic Surgeons. STS Adult Cardiac Surgery Database Risk Model Variables. Available at: http://www.sts.org/sites/default/files/documents/ Version2_73_RiskVariables.pdf. Accessed March 1, 2015.

7. Society of Thoracic Surgeons. Adult Cardiac Surgery Database v2.81 training manual. Available at: http://www.sts.org/sites/default/files/documents/JAN\% 20FAQ\%20TRAINING\%20MANUAL\%20.pdf. Accessed March 1, 2015.

8. Magee MJ, Herbert MA, Roper KL, Holper E, Dewey TM, Snelus T, et al. Pulmonary function tests overestimate chronic pulmonary disease in patients with severe aortic stenosis. Ann Thorac Surg. 2013;96:1329-35.

9. Chopard R, Meneveau N, Chocron S, Gilard M, Laskar M, Eltchaninoff H, et al. Impact of chronic obstructive pulmonary disease on Valve Academic Research Consortium-defined outcomes after transcatheter aortic valve implantation (from the FRANCE 2 Registry). Am J Cardiol. 2014;113:1543-9.

10. Faggiano P, Frattini S, Zilioli V, Rossi A, Nistri S, Dini FL, et al. Prevalence of comorbidities and associated cardiac diseases in patients with valve aortic stenosis: potential implications for the decision-making process. Int J Cardiol. 2012;159:94-9. 
11. Barreto-Filho JA, Wang Y, Dodson JA, Desai MM, Sugeng L, Geirsson A, et al. Trends in aortic valve replacement for elderly patients in the United States, 1999-2011. JAMA. 2013;310:2078-85.

12. Makkar RR, Fontana GP, Jilaihawi H, Kapadia S, Pichard AD, Douglas PS, et al. Transcatheter aortic-valve replacement for inoperable severe aortic stenosis. N Engl J Med. 2012;366:1696-704.

13. Leon MB, Smith CR, Mack M, Miller DC, Moses JW, Svensson LG, et al. Transcatheter aortic-valve implantation for aortic stenosis in patients who cannot undergo surgery. N Engl J Med. 2010;363:1597-607.

14. Smith CR, Leon MB, Mack MJ, Miller DC, Moses JW, Svensson LG, et al. Transcatheter versus surgical aortic-valve replacement in high-risk patients. N Engl J Med. 2011;364:2187-98.

15. Rodés-Cabau J, Webb JG, Cheung A, Ye J, Dumont E, Osten M, et al. Long-term outcomes after transcatheter aortic valve implantation: insights on prognostic factors and valve durability from the Canadian multicenter experience. $J \mathrm{Am}$ Coll Cardiol. 2012;60:1864-75.

16. Moat NE, Ludman P, de Belder MA, Bridgewater B, Cunningham AD, Young CP, et al. Long-term outcomes after transcatheter aortic valve implantation in high-risk patients with severe aortic stenosis: the UK TAVI (United Kingdom Transcatheter Aortic Valve Implantation) Registry. J Am Coll Cardiol. 2011;58:2130-8.

17. O'Brien SM, Shahian DM, Filardo G, Ferraris VA, Haan CK, Rich JB, et al. The Society of Thoracic Surgeons 2008 cardiac surgery risk models, part 2: isolated valve surgery. Ann Thorac Surg. 2009;88(1 Suppl):S23-42.

18. Tamburino C, Capodanno D, Ramondo A, Petronio AS, Ettori F, Santoro G, et al. Incidence and predictors of early and late mortality after transcatheter aortic valve implantation in 663 patients with severe aortic stenosis. Circulation. 2011;123:299-308.

19. Jha AK, Joynt KE, Orav EJ, Epstein AM. The long-term effect of premier pay for performance on patient outcomes. N Engl J Med. 2012;366:1606-15.

20. Adabag AS, Wassif HS, Rice K, Mithani S, Johnson D, Bonawitz-Conlin J, et al. Preoperative pulmonary function and mortality after cardiac surgery. Am Heart J. 2010;159:691-7.

21. Ad N, Henry L, Halpin L, Hunt S, Barnett S, Crippen P, et al. The use of spirometry testing prior to cardiac surgery may impact the Society of Thoracic Surgeons risk prediction score: a prospective study in a cohort of patients at high risk for chronic lung disease. J Thorac Cardiovasc Surg. 2010; 139:686-91.

22. Nissinen J, Biancari F, Wistbacka JO, Niemi R, Loponen P, Tarkiainen P, et al. Pulmonary function and immediate outcome of patients undergoing aortic valve replacement. J Heart Valve Dis. 2009;18:374-9.

Key Words: aortic valve replacement, pulmonary function tests, preoperative evaluation, aortic stenosis, TAVR

\section{Discussion}

Dr T. Dewey (Dallas, Tex). Thank you. I'd like to congratulate Dr Henn and his coauthors from Washington University on an interesting and well-presented study. I'd also like to thank the Association for the opportunity to comment on this paper.

Pulmonary function tests are one of the few diagnostic studies that make two specific demands on the patients. First, they must be compliant with somewhat detailed instructions in the performance of the test, and second, they must give maximal effort in order to achieve accurate results. Thus, conditions such as frailty and debility, severe heart failure, neurocognitive decline from dementia or previous strokes or age or musculoskeletal abnormalities such as kyphoscoliosis can have profound effects on the results on these tests but no actual correlation with intrinsic lung disease.
I have 3 questions. The first of which would be, one would expect that your patients with moderate to severe chronic lung disease would have a higher incidence of smoking, longer post-procedure intubation times, and more frequent readmission to the ICU for respiratory complications. However, neither in your surgical AVR group or your transcatheter AVR group demonstrated this. Can you comment on this finding especially in light of the fact that based on their pulmonary function tests they should have had higher risks for each of these complications?

Dr Henn. Thank you, Dr Dewey, for reviewing our work and for your excellent question. We were also surprised to find no correlation between those with moderate or severe lung disease and history of smoking, intubation time, or ICU respiratory readmissions in the individual SAVR and TAVR populations. These findings are consistent with the notion that the suspicion of underlying lung disease based on clinical history is not very good at predicting lung disease when the lung disease is diagnosed by STS criteria and PFTs. One would usually suspect bad lung disease if a patient comes into the office who is a chronic smoker, however our data suggest this may not necessarily be the case.

When combining both the TAVR and SAVR population, there actually was a significant difference in moderate to severe lung disease compared to none and mild lung disease in current or chronic smokers. Those with moderate to severe lung disease had 58\% smokers while those with none or mild had $49 \%$ smokers.

Prolonged intubation did not reach significance in the combined group, but there was a trend toward more prolonged intubations in the moderate or severe lung disease group.

Finally, respiratory readmissions to the ICU were significantly different when looking at the combined TAVR and SAVR population. We suspect this did not reach significance in the individual populations because of the relatively low numbers of readmissions in each group.

Dr Dewey. Sure. Second question, pulmonary function tests in a high-risk group of patients often appear to be more a marker of severity of illness and not particularly a predictor of perioperative pulmonary complications. As such, how would you recommend using this data in terms of your decision-making when deciding whether to offer a patient a surgical aortic valve versus a transcatheter aortic valve or even a transcatheter aortic valve and deciding on the approach, either transfemoral or an alternative access?

Dr Henn. Thank you for that question. This is something we are interested in evaluating in our patient population. Like most centers, our preferred approach is transfemoral, but it would be very interesting to evaluate whether preoperative PFTs have affected our choice in alternative access routes. 
In terms of this particular study, we didn't necessarily compare TAVR to SAVR in outcomes. However, we do routinely use preoperative PFTs to help risk stratify patients and to help decide between TAVR or SAVR.

Dr Dewey. And, finally, longer-term survival appeared to be significantly affected by having either moderate or severe chronic lung disease in both the surgical AVR and the transcatheter AVR groups. However, these groups also had significantly higher STS predicted risk scores in differences between the groups in terms of peripheral vascular disease and New York Heart Association Class, which also is directly related to poor survival.

Do you have any data that indicates that these late deaths could be directly attributable to pulmonary complications within these groups?

Dr Henn. That's a great question, but we were unable to evaluate pulmonary complications resulting in death because of the limitations in identifying true cause of death in this retrospective study.

Dr Dewey. Thank you.

Dr G. Whitman (Baltimore, Md). Dr Henn, I have a slightly different question. As a result of the trial for the TAVR patients, we performed pulmonary function studies on patients who normally would not have gotten them because their clinical history would not have indicated a need for them. A quarter of these patients, though, had moderate to severe COPD as defined by an FEV1 of less than $60 \%$ or less than $50 \%$.

Were these results to have been entered into the STS database, the individual's expected mortality would have risen. I think you even showed an increased mortality rate of 6 to $8 \%$. This generalizes to CABG surgery as well. An 80 -year-old diabetic woman who is having an urgent operation has a $2 \%$ mortality, but if she has just moderate COPD, she has a $4 \%$ mortality.

It seems to me that your data suggests that all of our patients, in order to be appropriately risk stratified, should be getting pulmonary function studies. This is crucial in determining quality of care, as one of the ways we judge that is via our $\mathrm{O} / \mathrm{E}$ ratios. Is that a reasonable thing to expect of programs when, in fact, in the Choosing Wisely campaign, for example, we are being advised to forego unnecessary pulmonary function studies?

Dr Henn. Thank you for that excellent question. Certainly having full knowledge of a patient's risk prior to taking them to the operating room is ideal. Particularly if you look at the future of medicine with the possibility of reimbursement for outcomes, having an adequate picture of how risky an operation is going to be is extremely important now more than ever. Our data suggest that there is a significant portion of this population where we are underestimating the risk of intervention.

Whether it's going to be financially feasible to do preoperative PFTs in everybody, particularly in the aortic stenosis population where your preoperative PFTs may be a surrogate for underlying heart failure, certainly needs to be evaluated. We definitely do know that abnormal preoperative PFTs is a predictor of mortality, so certainly it would be reasonable to get preoperative PFTs in patients with aortic stenosis to accurately stratify their risk.

Dr Whitman. Thank you very much. 

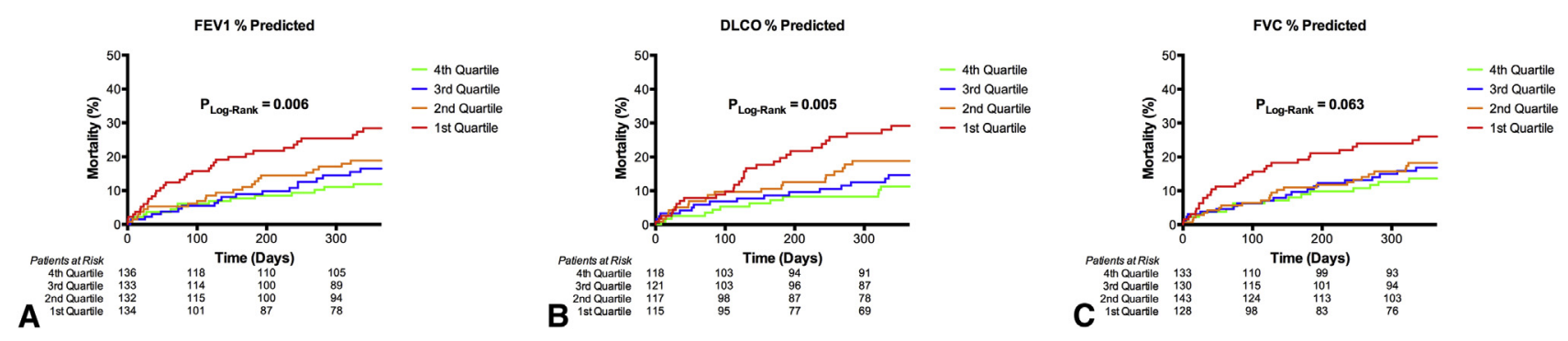

FIGURE E1. PFT metrics and mortality after AVR. Time-to-event curves are shown based on Kaplan-Meier estimates when patients who underwent TAVR or SAVR are stratified into quartiles based on (A) percent predicted forced expiratory volume in 1 second (FEV1), (B) diffusion capacity of the lung for carbon monoxide $(D L C O)$, and $(\mathrm{C})$ forced vital capacity $(F V C)$.

TABLE E1. Kaplan-Meier survival estimates for chronic lung disease and mortality after aortic valve replacement

\begin{tabular}{|c|c|c|c|c|}
\hline Procedure & None & Mild & Moderate & Severe \\
\hline \multicolumn{5}{|c|}{ TAVR and SAVR } \\
\hline $30 \mathrm{~d}$ & $0.97(0.93-0.98)$ & $0.96(0.91-0.98)$ & $0.94(0.86-0.97)$ & $0.91(0.85-0.95)$ \\
\hline $6 \mathrm{mo}$ & $0.93(0.88-0.96)$ & $0.91(0.84-0.95)$ & $0.83(0.73-0.90)$ & $0.76(0.67-0.83)$ \\
\hline $1 \mathrm{y}$ & $0.88(0.83-0.92)$ & $0.83(0.74-0.89)$ & $0.78(0.67-0.86)$ & $0.69(0.59-0.77)$ \\
\hline \multicolumn{5}{|l|}{ TAVR only } \\
\hline $30 \mathrm{~d}$ & $0.97(0.90-0.99)$ & $0.97(0.87-0.99)$ & $0.95(0.82-0.99)$ & $0.90(0.79-0.95)$ \\
\hline $6 \mathrm{mo}$ & $0.92(0.83-0.96)$ & $0.88(0.76-0.94)$ & $0.85(0.70-0.93)$ & $0.75(0.62-0.84)$ \\
\hline $1 \mathrm{y}$ & $0.87(0.78-0.93)$ & $0.80(0.67-0.88)$ & $0.80(0.64-0.90)$ & $0.64(0.50-0.75)$ \\
\hline \multicolumn{5}{|l|}{ SAVR only } \\
\hline $30 \mathrm{~d}$ & $0.97(0.92-0.99)$ & $0.97(0.88-0.99)$ & $0.93(0.81-0.98)$ & $0.93(0.83-0.97)$ \\
\hline $6 \mathrm{mo}$ & $0.95(0.88-0.98)$ & $0.95(0.85-0.98)$ & $0.82(0.66-0.91)$ & $0.78(0.64-0.87)$ \\
\hline $1 \mathrm{y}$ & $0.89(0.82-0.94)$ & $0.86(0.73-0.93)$ & $0.76(0.58-0.87)$ & $0.75(0.61-0.85)$ \\
\hline
\end{tabular}

Data are presented as survival proportion (95\% confidence interval). TAVR, Transcatheter aortic valve replacement; SAVR, surgical aortic valve replacement. 
TABLE E2. Kaplan-Meier survival estimates for pulmonary function test metrics and mortality after aortic valve replacement

\begin{tabular}{|c|c|c|c|c|}
\hline Metric & Quartile 1 & Quartile 2 & Quartile 3 & Quartile 4 \\
\hline \multicolumn{5}{|l|}{ FEV1 } \\
\hline $30 \mathrm{~d}$ & $0.92(0.86-0.96)$ & $0.95(0.89-0.97)$ & $0.98(0.93-0.99)$ & $0.96(0.91-0.98)$ \\
\hline $6 \mathrm{mo}$ & $0.78(0.70-0.85)$ & $0.88(0.81-0.93)$ & $0.91(0.84-0.95)$ & $0.92(0.86-0.96)$ \\
\hline $1 \mathrm{y}$ & $0.72(0.62-0.79)$ & $0.81(0.73-0.87)$ & $0.83(0.75-0.89)$ & $0.88(0.81-0.93)$ \\
\hline \multicolumn{5}{|l|}{ DLCO } \\
\hline $30 \mathrm{~d}$ & $0.94(0.88-0.97)$ & $0.95(0.89-0.98)$ & $0.97(0.91-0.99)$ & $0.97(0.92-0.99)$ \\
\hline $6 \mathrm{mo}$ & $0.80(0.71-0.87)$ & $0.88(0.81-0.93)$ & $0.91(0.85-0.95)$ & $0.93(0.86-0.96)$ \\
\hline $1 \mathrm{y}$ & $0.71(0.61-0.79)$ & $0.81(0.72-0.87)$ & $0.85(0.77-0.91)$ & $0.89(0.81-0.93)$ \\
\hline \multicolumn{5}{|l|}{ FVC } \\
\hline $30 \mathrm{~d}$ & $0.92(0.86-0.96)$ & $0.96(0.92-0.99)$ & $0.96(0.91-0.98)$ & $0.96(0.91-0.98)$ \\
\hline $6 \mathrm{mo}$ & $0.80(0.71-0.86)$ & $0.89(0.82-0.93)$ & $0.89(0.83-0.94)$ & $0.91(0.84-0.95)$ \\
\hline $1 \mathrm{y}$ & $0.74(0.65-0.81)$ & $0.82(0.74-0.87)$ & $0.83(0.75-0.89)$ & $0.86(0.79-0.91)$ \\
\hline
\end{tabular}

\begin{tabular}{|c|c|c|}
\hline $\begin{array}{c}\text { Pulmonary function test } \\
\text { metric }\end{array}$ & HR $(95 \%$ CI $) *$ & $P$ value \\
\hline FEV1 $\%$ predicted & $1.158(1.058-1.267)$ & .001 \\
\hline FVC\% predicted & $1.127(1.027-1.237)$ & .011 \\
\hline DLCO $\%$ predicted & $1.163(1.080-1.254)$ & $<.001$ \\
\hline
\end{tabular}

